\title{
Towards an Animal Model of Food Addiction
}

\author{
Johannes W. de Jong ${ }^{a} \quad$ Louk J.M.J. Vanderschuren ${ }^{a, b}$ Roger A.H. Adan ${ }^{a}$ \\ ${ }^{a}$ Rudolf Magnus Institute of Neuroscience, Department of Neuroscience and Pharmacology, \\ University Medical Center Utrecht, ${ }^{b}$ Department of Animals in Science and Society, \\ Division of Behavioral Neuroscience, Faculty of Veterinary Medicine, Utrecht University, \\ Utrecht, the Netherlands
}

\section{Key Words}

Animal models $\cdot$ Food $\cdot$ Motivation $\cdot$ Psychiatric aspects $\cdot$ Obesity $\cdot$ Addiction

\begin{abstract}
The dramatically increasing prevalence of obesity, associated with potentially life-threatening health problems, including cardiovascular diseases and type II diabetes, poses an enormous public health problem. It has been proposed that the obesity epidemic can be explained by the concept of 'food addiction'. In this review we focus on possible similarities between binge eating disorder (BED), which is highly prevalent in the obese population, and drug addiction. Indeed, both behavioral and neural similarities between addiction and BED have been demonstrated. Behavioral similarities are reflected in the overlap in DSM-IV criteria for drug addiction with the (suggested) criteria for BED and by food addiction-like behavior in animals after prolonged intermittent access to palatable food. Neural similarities include the overlap in brain regions involved in food and drug craving. Decreased dopamine D2 receptor availability in the striatum has been found in animal models of binge eating, after cocaine selfadministration in animals as well as in drug addiction and obesity in humans. To further explore the neurobiological basis of food addiction, it is essential to have an animal model to test the addictive potential of palatable food. A recently developed animal model for drug addiction involves three behavioral characteristics that are based on the DSM-IV criteria: i) extremely high motivation to obtain the drug, ii) difficulty in limiting drug seeking even in periods of explicit non-availability, iii) continuation of drug-seeking despite negative consequences. Indeed, it has been shown that a subgroup of rats, after prolonged cocaine selfadministration, scores positive on these three criteria. If food possesses addictive properties, then food-addicted rats should also meet these criteria while searching for and consuming food. In this review we discuss evidence from literature regarding food addiction-like behavior. We also suggest future experiments that could further contribute to our understanding of behavioral and neural commonalities and differences between obesity and drug addiction.
\end{abstract}




\section{Introduction}

The obesity epidemic has become a major threat to public health with 1 in 3 individuals being obese in the USA [1]. Obesity and its comorbidities that include cardiovascular disease, type 2 diabetes and several cancers are now the number one preventable cause of premature death in the USA [2]. The notion that food addiction may contribute to the high prevalence of obesity is gaining attention among scientists and mental health professionals [3-5]. To further investigate the addictive potential of food and its neurobehavioral underpinnings, an animal model of food addiction is essential. In this paper, we will briefly discuss behavioral and neurobiological similarities between overeating and drug addiction before we address the main question of this article: 'What is a valid animal model to determine whether food addition exists and if so, whether it resembles drug addiction on a neurobiological level?' We will briefly highlight several useful, widely employed models from the drug addiction field on which we base our proposed model to study food addiction.

Although the overarching aim of our research is to understand the neural and behavioral mechanisms of obesity in general, we here focus on binge eating disorder (BED) because of its high prevalence $(2.0 \%$ in males and $3.5 \%$ in females [6]) and possible behavioral resemblance to addiction. Clearly, similar arguments may be used to link addiction to other eating disorders or obesity in general [5]. We are, indeed, well aware of the fact that not all cases of obesity are caused by BED, that BED and obesity are not synonymous, and that BED and obesity have a distinct, if overlapping, neurobiological background [7].

Although it has become very prominent in recent years, the question whether overeating is a form of addiction is not new. Previously, several authors have theorized about whether food (or food components) can have addictive qualities, akin to drugs of abuse [3, $5,8,9]$. Proponents point out that both obesity and addiction involve similar neurobiological substrates and that there are several clinical and behavioral similarities. Opponents, on the other hand, indicate that addiction and overeating have a distinct etiology and that their treatment requires different strategies. Should food indeed be able to induce addiction-like behavior in vulnerable individuals, then this can have far-reaching consequences for the prevention and treatment of obesity. Obesity prevention programs could, for example, benefit from the success achieved by anti-smoking campaigns in Europe and North America, and potential treatments for obesity could include addiction treatments such as pharmacological interventions, cognitive behavioral therapy, and 12-step programs (although a 12-step program for obesity can, of course, not aim for complete abstinence of food) [10].

\section{Similarities between BED and Addiction in Humans}

BED is an eating disorder characterized by recurrent episodes of uncontrolled eating (binges). It is highly prevalent in obese individuals [11]. BED differs from other eating disorders in that no effort is made to compensate for the excess of energy intake by purging or intense exercise [12]. BED is currently not described in the DSM-IV itself, but in its appendix B which deals with possible new diagnostic categories. Suggested diagnostic criteria for BED are listed in table 1. An analysis of the DSM-IV criteria reveals similarity with drug addiction (which is termed substance dependence in the DSM-IV). Note, however, that the potential DSM criteria for BED remain subject to debate $[13,14]$.

According to DSM-IV [12], substance dependence is diagnosed when 3 of 7 criteria listed in table 1 have been met. The occurrence of either withdrawal symptoms or tolerance is indicative of physical dependence to drugs. Although physical dependence may not be a useful concept in the context of obesity, since all animals are physically dependent on food, 
Table 1. Diagnostic criteria for addiction (as defined in the DSM-IV) and the corresponding diagnostic criteria for BED

\begin{tabular}{ll}
\hline Substance dependence (addiction) & BED \\
\hline Withdrawal symptoms & \\
\hline Tolerance & \\
\hline Taken larger amount and longer than intended & $\begin{array}{l}\text { During episodes: a sense of lack of control } \\
\text { Eating until uncomfortably full } \\
\text { Eating large amounts of food when not feeling hungry } \\
\text { Eating larger than normal amounts in a short period of } \\
\text { time }\end{array}$ \\
\end{tabular}

Persistent desire, repeated unsuccessful attempts to quit

\begin{tabular}{ll}
\hline $\begin{array}{l}\text { Much time spend to obtain, use and recover from use } \\
\begin{array}{l}\text { Social, occupational or recreational activities given up in Eating alone because being embarrassed by how much } \\
\text { favor of use }\end{array}\end{array}$ & $\begin{array}{l}\text { Binge eating occurs at least two days per week } \\
\text { one is eating }\end{array}$ \\
\hline $\begin{array}{l}\text { Continued use despite knowledge of adverse } \\
\text { consequences }\end{array}$ & $\begin{array}{l}\text { Marked distress regarding binge eating is present } \\
\text { Feeling disgusted with oneself, depressed or very guilty } \\
\text { after overeating } \\
\text { The binges are not associated with any type of compen- } \\
\text { satory mechanism such as purging }\end{array}$ \\
\hline
\end{tabular}

it has been shown in animal experiments that tolerance and withdrawal may arise after extended intermittent access to palatable food, as will be discussed in the following sections [15-18]. The remaining five DSM-IV criteria for substance dependence relate to loss of control over drug intake. As can be seen in table 1, some of the criteria for BED markedly overlap with criteria for addiction, and loss of control over food intake is also a major element in BED. For one, in both drug addiction and BED the subject persists in destructive food- or drug-directed behavior while consciously aware of its deleterious consequences [12].

Table 1 lists the diagnostic criteria for addiction (according to DSM-IV) and the corresponding diagnostic criteria for BED. This approach is based on Volkow and O'Brien [5], who designed a similar table comparing addiction to obesity in general.

\section{Behavioral Similarities}

As can be gleaned from table 1, addiction shares several behavioral characteristics with overeating, and especially with BED. In both drug addiction and BED, subjects lose control over intake [19]. Gearhardt et al. [20] have recently developed a questionnaire, the Yale Food Addiction Scale (YFAS), to assess food addiction. The group of individuals that scored high on the YFAS also scored high on measures for BED, childhood attention deficit/hyperactivity disorder (ADHD), and severe depression [21]. It is interesting to note that ADHD and depression have also been associated with substance dependence [22-26].

Not all individuals exposed to drugs of abuse (or palatable food) lose control over behavior. Highly addictive drugs like cocaine are used on a regular basis in certain environments, but not all involved individuals become addicted $[27,28]$. The same is, of course, true 
for palatable food. The entire western population is exposed to an environment where palatable (energy-dense) food is constantly available, but only a subgroup of individuals will lose control over food intake and become obese and/or develop BED. Several risk factors for addiction have been identified, including genetic factors (reviewed in [29]), and impulsivity.

Individuals displaying high levels of impulsivity have an increased risk to become addicted to drugs and to develop obesity [30-35]. Interestingly, the relationship between addiction and impulsivity is bidirectional, as indicated by the fact that prolonged exposure to drugs results in impaired impulse control $[32,36]$. It has been shown that impulsivity is a predictor of the treatment outcome in obese children [34, 35, 37, 38] and in addiction [3943]. One potential behavioral mechanism underlying the relationship between impulsivity and addiction is the fact that impulsive individuals can be more sensitive to immediate gratification (in fact, intolerance to delay of reward is a prominent form of impulsivity) and less sensitive to long-term adverse consequences of behavior, which may contribute to losing control over food and/or drug intake.

\section{Neurobiological Similarities}

Both food and drugs can be the subject of intense craving. Below, we discuss several examples of functional neuroimaging studies investigating food and drug craving, the neural substrates of which display remarkable overlap. For an extensive review on the neurocircuitry of drug craving and addiction see [44, 45].

In studies of food and drug craving, measures of brain activity have been obtained using either positron emission tomography (PET) [46] or functional magnetic resonance imaging (fMRI) $[47,48]$. In these studies, craving was provoked using a visual presentation of the craved substance [48], a tactile drug cue (e.g. a marijuana pipe, as used by Filbey et al. [47]), or a verbal recount of a drug-related experience of the participant (Kilts et al. [46]).

Several studies have shown involvement of the orbital frontal cortex (OFC), prefrontal cortex (PFC), anterior cingulate, nucleus accumbens, amygdala, and insula in drug craving [46-49]. These regions involved in drug craving likely also mediate craving for natural rewards, including sex [50] and food [48]. Indeed, there is striking overlap between the regions activated during drug and food craving, since the insula, nucleus accumbens, anterior cingulate, amygdala, and OFC have also been implicated in food craving. When craving was self-induced by subjects, increased activity was found in the hippocampus, caudate, and insula [51]. Craving for chocolate (using pictures of chocolate or letting participants taste chocolate) has been associated with increased activity in the ventral striatum, subgenual cingulate, and OFC [52].

Suppression of craving, which will aid in remaining in control over intake, involves the dorsolateral PFC (DLPFC), which has been widely implicated in cognitive control over behavior [53]. When subjects were asked to suppress food or tobacco craving, activity in the accumbens, VTA, amygdala, and cingulate cortex decreased while activity in the DLPFC increased [48]. Interestingly, both the fMRI data and the behavioral (craving) data from this study showed striking similarities in the modulation of craving for drugs and food. The DLPFC was implicated in food addiction in a study by Gearhardt et al. [54] that investigated the neural correlates of food addiction as measured with the recently developed YFAS scale (see above). This study found increased activation in the DLPFC as well as in the caudate in individuals with a high food addiction score, during the anticipation of the receipt of palatable food. The role of the DLPFC in eating disorders has been explored in a clinical study in which participants with bulimic disorders where exposed to repetitive transcranial stimulation (TMS) of the DLPFC. These patients reported decreased craving immediately after TMS and fewer binge eating episodes in the $24 \mathrm{~h}$ following TMS, as compared to patients who received sham TMS [55]. Thus, craving for food and drugs appears to involve comparable neural substrates [56]. 
Table 2. Measuring addiction-like behavior

\begin{tabular}{ll}
\hline What to measure? & How to measure? \\
\hline Tolerance & $\begin{array}{l}\text { cross-tolerance with opioids, increased self-stimulation threshold } \\
\text { Drugs: }[97,99] \text { (among many others) } \\
\text { Food: }[19,93,98]\end{array}$ \\
\hline Withdrawal & $\begin{array}{l}\text { observing withdrawal symptoms, e.g. teeth chattering and increased } \\
\text { anxiety } \\
\text { drugs: }[126] \text { (among many others) } \\
\text { food: [16,18] }\end{array}$ \\
\hline Extremely high motivation & $\begin{array}{l}\text { progressive ratio schedule, in which animals have to exert increasingly } \\
\text { more work to obtain a reward } \\
\text { drugs: }[76,112-114] \\
\text { food: }[117,118]\end{array}$ \\
\hline Difficulty limiting intake & $\begin{array}{l}\text { limited access paradigm, in which seeking responses during signaled } \\
\text { non-availability are measured } \\
\text { drugs: }[71] \\
\text { food: [119] }\end{array}$ \\
\hline Continued use despite harmful & $\begin{array}{l}\text { reward seeking associated with (conditioned) punishment } \\
\text { drugs: }[70,71,74] \\
\text { food: [98, 122-124] }\end{array}$ \\
\hline
\end{tabular}

Regarding similarities in the neurobiological background of food and drug addiction, dopamine D2 receptor (D2R) availability may play a role in both [10]. Indeed, PET studies have shown decreased D2R availability in the striatum in both drug-addicted individuals and morbidly obese patients [10,57-59] An explanation for these findings is that decreased D2R availability results in a hypofunctioning reward system, and 'addicted' individuals compensate for this effect by consuming large amounts of rewarding substances such as food and drugs. The question remains whether this decreased D2R availability is an effect or the cause of addiction. Apartfrom the animal studies investigating this question (discussed in the following sections), there is some human data correlating genetic predisposition with decreased D2R availability and reward hypofunction in obesity [60] and addiction [61], but not necessarily with BED [7]. There is also evidence to suggest that decreased D2R density in the striatum both contributes to the development of addictive behavior [62-65], and is a consequence of prolonged drug use $[66,67]$. Human studies have shown that decreased D2R availability in the striatum can be a predictor of self-reported 'liking' of an intravenous injection of methylphenidate $[64,65]$. Conversely, decreased D2R availability was shown to be a consequence of prolonged drug use in studies investigating cocaine self-administration in non-human primates [66, 67].

Brain opioid neurotransmission is also involved in drug addiction and BED. Opioids play an important role in hedonic appreciation ('liking') of food, and they have particularly been implicated in the intake of palatable food $[68,69]$. The opioid receptor antagonist naloxone reduces appetite, in particular in patients with a history of binging [70, 71]. In addition, there is an increased prevalence of the A118G polymorphism of the $\mu$-opioid receptor in BED patients [7]. This indicates an important role for the opioid system in BED, mimicking its 
role in drug addiction, where the $\mu$-opioid receptor has been shown to mediate the rewarding aspects of opioids, ethanol, nicotine, and probably psychostimulants (as reviewed in [72]). Furthermore, the opioid system has been implicated in withdrawal for both drugs and food, as discussed in the following sections.

\section{Animal Models of Drug Addiction}

There has been a plethora of experiments investigating several aspects of drug addiction, including the motivation to obtain a drug and the process of relapse to drug seeking after extinction of self-administration [73, 74]. This has tremendously contributed to our understanding of the neural and behavioral underpinnings of drug seeking and taking $[44,45,75]$. In this review, we focus on recently developed animals models that incorporate multiple DSM-IV criteria to identify animals that express addiction-like behavior.

Animals will readily self-administer and respond at high levels for food or drugs of abuse $[74,76]$, but being extremely motivated to obtain a reward is only one aspect of the addiction syndrome [12]. Experimental approaches of addiction, or loss of control over intake (see below), also involve setups in which seeking and/or taking rewards is met with aversive consequences. Examples of such approaches include punishing reward seeking with mild electric shock [77, 78], adulterating an ingested reward with the bitter-tasting quinine [79-81], or exposing the animal to a cue that has previously been associated with electric shock [82]. In addition, models for compulsive drug use usually take two more points into account. First, addiction develops after chronic drug use. Although a drug may be rewarding and evoke motivated behavior on initial contact, loss of control and compulsive behavior only arises after prolonged excessive drug use [79-83]. Second, there is substantial variability in the susceptibility to addictive behavior in animals and humans. Thus, even after extended access to a reward, only a subgroup of the exposed individuals (humans or animals) will lose control over intake [28, 77, 78, 84, 85]. Several studies have tried to identify neural or behavioral traits that predict whether or not an individual is likely to lose control over intake and become addicted.

The pioneering work by Piazza et al. [86] identified so-called 'high' and 'low' responders to novelty, in which high responders showed a stronger psychomotor response to a novel environment. High responders acquired amphetamine self-administration faster than low responders and showed enhanced cocaine self-administration in a subsequent study [87]. Studies in recent years have focused on impulsivity as a predictive factor for addictive behavior (reviewed in $[36,88]$ ). Thus, Dalley et al. [63] used the five-choice serial reaction time task to identify impulsive rats. They showed that impulsivity in this task predicts escalation of cocaine intake (but not heroin intake [89]). High impulsive rats also displayed decreased D2R availability in the ventral striatum. Belin et al. [85] subsequently showed that impulsive rats in the five-choice serial reaction time task were more prone to develop addiction-like behavior for cocaine when addiction criteria based on DSM-IV were used (see below). Interestingly, impulsivity did predict addiction-like behavior, but not acquisition of cocaine self-administration, whereas the locomotor response to novelty (which did not correlate with impulsivity) predicted the acquisition of cocaine self-administration, but not addiction-like behavior $[85,90]$. Together, these studies $[63,85]$ also indicate that low D2R availability is a predictor of escalated cocaine use ultimately culminating in addictive behavior [67]. The predictive value of impulsivity for addictive behavior is supported by other studies demonstrating that enhanced impulsive behavior is associated with different aspects of cocaine, nicotine, and ethanol (but not heroin) self-administration [91-94]. Another approach to identify an addiction-susceptible subgroup of animals has been 
developed by Ahmed and colleagues $[84,95]$. These researchers used a choice paradigm to show that, even after chronic exposure to cocaine, $90 \%$ of all Wistar rats prefer a sweet saccharin solution over a cocaine infusion $[84,95,96]$. This appears in contrast to the behavior of addicted individuals who (by definition) sacrifice non-drug rewards (like palatable food or social interaction) in favor of drug-related activities [12]. Interestingly, about $10 \%$ of the animals in these studies did express a preference for cocaine over saccharin, which is comparable to the proportion of human cocaine users who will go on to meet the criteria for addiction. It remains to be demonstrated, of course, whether the $10 \%$ cocainepreferring animals will also show 'addiction-like' behavior for cocaine.

Based on the DSM-IV criteria for substance dependence [12] and the research previously described, three criteria, that relate to escalated drug intake and the failure to exert control over intake [78], have been proposed for addiction-like behavior in animals. First: an extremely high motivation to seek the drug. Second: difficulty limiting drug intake. Third: continuation of drug seeking despite aversive consequences. Deroche-Gamonet et al. [78] showed that a subgroup of rats, after chronic cocaine self-administration, scored positive on these three criteria. These animals differ from addiction-resistant animals in that they are highly impulsive [85] and have a persistent impairment in NMDAR-mediated long-term depression in the nucleus accumbens [97]. In order to assess the functional similarity in drug and food addiction, a similar group of 'food addiction-like behavior'-expressing animals should be identified. Subsequently, this group of 'food-addicted' animals can be compared to drug-addicted animals to evaluate whether or not the biochemical and cellular changes in food and drug addiction-like behavior are similar.

\section{Models for Aspects of Food Addiction-Like Behavior and Neurochemical Changes Resembling Addiction}

There is ample evidence from animal studies to suggest that addiction-like behavior for food exists. Here, we briefly review experimental models that can be used to capture food addiction-like behavior. We will first discuss the seven DSM-IV criteria for addiction. Five of these relate to loss of control over drug intake. Loss of control can be studied in animals using the, previously described, 3-criteria model designed by Deroche-Gamonet et al. [78]. We will therefore also discuss these 3 criteria and how they can be assessed.

\section{Tolerance}

In the context of drug addiction, tolerance refers to the fact that after repeated drug use a larger quantity of the drug is needed to obtain the desired subjective effect or that the (positive) effect of a given drug dose decreases with repeated drug use. Interestingly, after extended access to a palatable diet, it has been shown that rats indeed increase their food intake [98], although mechanisms other than tolerance could also explain this finding. There is also data to suggest the existence of cross-tolerance between sweet solutions and opioids $[18,99]$. Reward tolerance has also been studied measuring reward thresholds in an intracranial self-stimulation setup. This reward threshold is defined as the minimum electrical current needed to maintain stable self-stimulation $[100,101]$. Acute treatment with drugs of abuse lowers the reward threshold, indicative of the rewarding properties of drugs [102]. However, the reward threshold is increased during withdrawal after extended drug treatment, likely as a result of desensitization of brain reward pathways [101,103]. A similar effect on self-stimulation thresholds has been demonstrated after withdrawal from a highly palatable 'cafeteria style diet' [104]. The increase in self-stimulation threshold after withdrawal from palatable food or drugs has been associated with decreased D2R activity $[104,105]$. 


\section{Withdrawal}

Pioneering work of Hoebel and colleagues $[16,106]$ provided evidence for withdrawal phenomena in rats that were exposed to $12 \mathrm{~h} / 12 \mathrm{~h}$ cycles of food deprivation and access to a sweet solution. When denied access to sucrose, rats exposed to these diet cycles, will binge and display signs of withdrawal such as increased anxiety (as assessed in an elevated plus maze) and increased teeth chattering [15]. These withdrawal symptoms were shown to be inducible by treatment with the opioid receptor antagonist naloxone and to be associated with an increase in D1R and $\mu$-opioid receptor binding and a decrease in D2R binding [15, 107]. A decrease in D2R binding following intermittent sucrose administration was also observed by others [108].

Withdrawal from drugs of abuse and the associated changes in behavior have been suggested to depend on activation of brain stress mechanisms [109]. Conversely, stress can play an important role in the development of overeating $[110,111]$. Indeed, there is an important interaction between food binging and stress. Binge eating can be triggered by foot shock stress $[112,113]$ or the frustrating presence of an unreachable (but easily visible) palatable treat [114]. Food restriction itself is also stressful and this may promote binge eating [115]. In addition, animals withdrawn from intermittent access to palatable food show withdrawal signs (increased anxiety and motivational deficits) that are attenuated by treatment with a CRF receptor antagonist [17]. Stress is also widely used to reinstate extinguished drug seeking in an animal model of relapse to drug use [116, 117]. Intriguingly, in these models stress does not reinstate chow or sucrose seeking. This may indicate that mere sucrose self-administration does not result in the same behavioral changes as drug self-administration or intermittent palatable food intake coupled with food restriction does.

\section{Extremely High Motivation to Obtain the Reward}

A widely used method to measure the motivation to obtain food or drugs is the so-called progressive ratio schedule of reinforcement, in which animals have to make an increasing number of operant responses for every subsequent reward [76]. Indeed, after prolonged cocaine or heroin self-administration, the motivation for drugs under a progressive ratio schedule of reinforcement has been shown to increase [78, 118-120] (but see [121, 122]). Likewise, it has been shown that rats show an increased motivation to obtain a sucrose reward under a progressive ratio schedule after chronic exposure to a high-fat, high-sucrose (HFHS) choice diet [123]. Other studies have shown that limited (1 h, 3 days a week) access to fat also increases the motivation for food [124].

\section{Difficulty Stopping Use or Limiting Intake}

This aspect of addictive behavior can be investigated using a so-called 'time-out' model. In this paradigm, seeking responses are measured in a designated period of an operant selfadministration session when the non-availability of a reward is explicitly signaled to the animals. It has been shown that rats, after extended access to cocaine, continue to seek cocaine when this is not available [78]. Likewise, Ghitza et al. [125] demonstrated that, with prolonged training, animals exposed to a palatable diet increase their food seeking responses during time-out periods, indicating that they develop a 'difficulty limiting' food seeking.

\section{Continued Use Despite Adverse Consequences}

Recent studies have demonstrated that this characteristic of addictive behavior also occurs in laboratory animals. Vanderschuren et al. [82] showed that, after prolonged (but not limited) cocaine self-administration, rats will continue to seek cocaine in the presence of an aversive conditioned stimulus (a tone previously paired with foot shock). However, 
after prolonged sucrose self-administration, suppression of sucrose seeking by the foot shock conditioned stimulus still occurred. Comparable results were obtained in devaluation experiments (in which an ingested reward is paired with lithium chloride-induced illness). In these studies, sucrose seeking was sensitive to lithium chloride-induced devaluation, whereas responding to alcohol [126] or cocaine was not [127]. Again, these data show that self-administered sucrose does not have the same addictive potential as drugs of abuse. Comparable conditioned aversion paradigms have, however, been used on several occasions to show that seeking palatable food (usually a combination of fat and sugar, instead of just sugar) can become resistant to punishment $[104,128]$. For example, Johnson and Kenny [104] showed that after extended access to a 'cafeteria style diet', food seeking in rats became insensitive to presentation of a conditioned aversive stimulus. Using a conditioned suppression paradigm akin to that used by Vanderschuren et al. [82], Latagliata et al. [128] showed that food restricted animals continue to seek food regardless of its aversive consequences. Interestingly, they showed that noradrenaline depletion of the medial PFC prevented the occurrence of food seeking despite aversive consequences, i.e. restored conditioned suppression. These data are consistent with the notion that the PFC mediates 'top-down' inhibitory influence over maladaptive, addictive behavior [48].

In addition to conditioned aversion, several models have been developed that measure sensitivity to unconditioned punishment. Pelloux et al. [77] showed that a subgroup of rats, after chronic cocaine self-administration, continue to seek cocaine whilst taking the risk of receiving a foot shock as a consequence. Oswald et al. [129] designed a model in which animals have a choice between standard chow and palatable food paired with foot shock. It appeared that rats that easily binge when exposed to palatable food (binge eating-prone rats) were significantly less sensitive to the aversive effect of foot shock and continued to consume the palatable food as compared to binge eating-resistant rats.

Using a related punishment setup, Heyne et al. [130] showed that inflexible intake of palatable food occurs after lengthy intake of a choice diet. In these experiments, rats were given the choice between a 'cafeteria diet' (consisting of bacon, sausage, cheesecake, pound cake, frosting, and chocolate) and standard chow. After several weeks, a subgroup of animals continued to ingest the cafeteria diet even when it was adulterated with quinine (a bittertasting substance). This can be interpreted as inflexible behavior $[79,131]$, which is a defining characteristic of addictive behavior, in the sense that subjects are unable to shift their thoughts and behavior away from drugs but continue to seek the drug despite knowledge of aversive consequences [12]. Interestingly, the animals that did cease to eat the cafeteria diet after quinine adulteration displayed another form of, perhaps, inflexible behavior in that they did not compensate for decreased energy intake by taking more of the standard chow. This 'inflexible' behavior is not indicative of 'addictive' behavior, but it is a form of 'inflexible behavior' in that these animals do not adequately respond to a changing environment (i.e. the adulteration of their preferred food), by acquiring their daily caloric ration from another source.

\section{Relapse and Cue-Induced Feeding}

Addiction is a chronic, relapsing disorder. In fact, the high risk of relapse to addictive behavior that former drug addicts run and that remains present after years of abstinence is perhaps the most insidious aspects of addiction. Animals cannot, in the strict sense relapse since they are not consciously aware of the disadvantages of drug seeking and taking. They can, however, reinstate responding for food or drugs, which is widely employed as an animal model for relapse [73]. Food seeking can be reinstated by non-contingent presentation of food, or response-contingent presentation of food-associated conditioned stimuli. Although reinstatement to food or drug seeking does not equate to addiction-like behavior, it has been 
shown that animals that had lost control over cocaine intake (as assessed using the 3-criteria model), were more prone to reinstatement of cocaine seeking [78], and the neural substrates of reinstatement of food and drug seeking overlap to some degree [133].

Besides provoking reinstatement of food seeking, food-associated cues can promote food intake itself. In so-called cue-induced feeding models, sated animals ingest chow following exposure to a food-associated conditioned cue. This was first demonstrated by Weingarten [134], who showed that sated rats resumed eating when exposed to a stimulus previously associated with meal delivery during food restriction. Another possibility involves exposing the animals to cues associated with palatable food or a tiny morsel of the palatable food itself [135]. It has been suggested that overeating in a western society may be mediated by a similar process caused by conditioned craving in response to food cues in our environment $[136,137]$.

\section{Conclusion and Future Perspectives}

The data from animal studies discussed above support the notion of addiction-like behavior directed at food. Both neurobiological (e.g. D2R down-regulation) and behavioral (increased intake, loss of control) similarities with drug addiction have been demonstrated.

Chronic ingestion of (large quantities of) palatable food may result in addiction-like behavior, as it occurs with drugs. Clearly, food addiction-like behavior may be dependent on the type of diet and the type of food reward the animals obtain. Especially relevant are limited access models, including the one used by Hoebel et al. [15] to show withdrawal and the one by Corwin et al. [124] to show both withdrawal and increased motivation for food. When rats are exposed to cycles of alternating periods of food restriction (dieting) and periods of exposure to (palatable) food, they will start to display binges on palatable food [138]. Indeed, alternating periods of dieting and binging on palatable food are highly prevalent in humans with BED [139]. Hagan et al. [112, 113] have suggested that a diet cycle model has face and construct validity for BED. The binges are characterized by increased intake of palatable food, but not standard chow intake. Therefore, they may be mediated by hedonic, but not homeostatic, control. Cifani et al. [114] provided support for the predictive validity of the diet cycle model by showing that several psychoactive drugs (sibutramine, fluoxetine, topiramate, and midazolam) have similar effects in the model and in patients with BED.

We propose that animals, after extended access to a limited-access paradigm, should be tested on the three criteria for addiction-like behavior comparable to the procedure employed for cocaine addiction by Deroche-Gamonet et al. [78]. If a subgroup of animals that is more likely to lose control over intake (based on these three criteria) can be identified, these animals can then be characterized to see whether or not their neural and behavioral makeup resembles drug addiction-prone animals. Several behavioral aspects should be taken into account to test whether food addiction-prone animals express the same altered behavior that drug addiction-prone animals do. For instance, in rats, impulsivity is a predictor for cocaine intake and addiction-like behavior $[63,85,88,92]$, nicotine and ethanol self-administration [91, 93], and sucrose seeking [140]. Is impulsivity also predictive of addiction-like behavior for food? Also, addiction-prone rats have a distinct pattern of drug intake when the drug is freely available, even before they display clear-cut signs of addictionlike behavior [141]. It would be of interest to see if this is also the case for food intake. Last, the expression of addiction-like behavior for cocaine has also been associated with increased reinstatement of cocaine seeking after extinction. It would therefore also be relevant to test if 'food addiction' is associated with augmented reinstatement of food seeking $[125,142]$. 
In this review we briefly alluded to neurobiological changes in (food) addiction, including differences in D1R, D2R, and $\mu$-opioid receptor expression. Once animals that express food addiction-like behavior have been identified, these systems can be further studied in the context of food addiction. As an example, neuronal activity following palatable food administration or anticipation to a palatable diet can be measured using immunohistochemistry for immediate early genes [143] or using (in- vivo) electrophysiology. Using these techniques, it can be investigated whether food-addicted animals rely on different neural networks for the expression of food-oriented behavior compared to addiction-resistant animals. Indeed, there is human data that indicates that food addicts rely differently on the dorsal lateral PFC and the caudate during anticipation of food [54]. Moreover, studies in nonhuman primates have shown that the brains of primates with a long history of cocaine administration respond differently to cocaine then animals with only limited experience with cocaine. One prominent neural change that has been identified is a shift in metabolic activity from the ventral to the dorsolateral striatum during cocaine self-administration in animals that self-administered cocaine for 1.5 years as compared to animals with limited self-administration experience [66, 144]. Likewise, it has been shown that the neural response to a methylphenidate challenge differs between cocaine addicts and control subjects [145]. Since the development of addictive behavior relies on concerted neural changes in the VTA, the striatum, the amygdala, and the PFC $[44,146]$, these circuits should be investigated accordingly.

In conclusion, the behavioral and neurobiological similarities between addiction and overeating (in particular BED) warrant further investigation. Of particular interest is the question whether the 'loss of control' over intake for both food and drugs involves comparable behavioral and neurobiological processes. To do this, applying pertinent models from the drug addiction field to the eating disorder field may provide vital information.

\section{Acknowledgements}

The current work has been supported and funded by the NeuroFAST Foundation (the integrated neurobiology of food intake, addiction and stress). NeuroFAST is funded by the European Union Seventh Framework Programme (FP7/2007-2013) under grant agreement $n^{\circ} 245009$.

\section{Disclosure Statement}

The authors declare no conflict of interest.

\section{References}

1 Flegal KM, Carroll MD, Ogden CL, Curtin LR: Prevalence and trends in obesity among US adults, 1999-2008. JAMA 2010;303:235-241.

- 2 Haslam DW, James WPT: Obesity. Lancet 2005;366:1197-1209.

- 3 Wilson GT: Eating disorders, obesity and addiction. Eur Eat Disord Rev 2010;18:341-351.

- 4 Corsica JA, Pelchat ML: Food addiction: true or false? Curr Opin Gastroenterol 2010;26:165-169.

5 Volkow ND, O’Brien CP: Issues for DSM-V: should obesity be included as a brain disorder? Am J Psychiatry 2007;164:708-710.

6 Hudson JI, Hiripi E, Pope HG, Kessler RC: The prevalence and correlates of eating disorders in the National Comorbidity Survey Replication. Biol Psychiatry 2007;61:348-358.

7 Davis CA, Levitan RD, Reid C, Carter JC, Kaplan AS, Patte KA, King N, Curtis C, Kennedy JL: Dopamine for 'wanting' and opioids for 'liking': a comparison of obese adults with and without binge eating. Obesity (Silver Spring) 2009;17:1220-1225. 
Davis C, Carter JC: Compulsive overeating as an addiction disorder. A review of theory and evidence. Appetite 2009;53:1-8.

9 Davis C, Claridge G: The eating disorders as addiction: a psychobiological perspective. Addict Behav 1998; 23:463-475.

10 Volkow ND, Wise RA: How can drug addiction help us understand obesity? Nat Neurosci 2005;8:555-560. Hudson JI, Lalonde JK, Berry JM, Pindyck LJ, Bulik CM, Crow SJ, McElroy SL, Laird NM, Tsuang MT, Walsh BT, et al: Binge-eating disorder as a distinct familial phenotype in obese individuals. Arch Gen Psychiatry 2006;63:313-319.

12 Association the American Psychiatric: DSM-IV-TR: Diagnostic and Statistical Manual of Mental Disorders, 4 th ed, 2000

$>13$ Cooper Z, Fairburn CG: Refining the definition of binge eating disorder and nonpurging bulimia nervosa. International J Eat Disrod 2003;34(suppl):S89-95.

14 Fairburn CG, Cooper Z: Eating disorders, DSM-5 and clinical reality. Br J Psychiatry 2011;198:8-10.

15 Colantuoni C, Rada P, McCarthy J, Patten C, Avena NM, Chadeayne A, Hoebel BG: Evidence that intermittent, excessive sugar intake causes endogenous opioid dependence. Obes Res 2002;10:478-488.

16 Avena NM, Rada P, Hoebel BG: Evidence for sugar addiction: behavioral and neurochemical effects of intermittent, excessive sugar intake. Neurosci Biobehav Rev 2008;32:20-39.

-17 Cottone P, Sabino V, Roberto M, Bajo M, Pockros L, Frihauf JB, Fekete EM, Steardo L, Rice KC, Grigoriadis DE, et al: CRF system recruitment mediates dark side of compulsive eating. Proc Natl Acad Sci U S A 2009;106: 20016-20020.

18 Cohen E, Lieblich I, Bergmann F: Effects of chronically elevated intake of different concentrations of saccharin on morphine tolerance in genetically selected rats. Physiol Behav 1984;32:1041-1043.

19 Corwin RL, Grigson PS: Symposium overview - food addiction: fact or fiction? J Nutr 2009;139:617-619.

-20 Gearhardt AN, Corbin WR, Brownell KD: Preliminary validation of the Yale Food Addiction Scale. Appetite 2009;52:430-436.

21 Davis C, Curtis C, Levitan RD, Carter JC, Kaplan AS, Kennedy JL: Evidence that 'food addiction' is a valid phenotype of obesity. Appetite 2011;57:711-717.

22 Wilens TE, Biederman J, Mick E, Faraone SV, Spencer T: Attention deficit hyperactivity disorder (ADHD) is associated with early onset substance use disorders. J Nerv Ment Dis 1997;185:475-482.

23 Wilens TE: Attention-deficit/hyperactivity disorder and the substance use disorders: the nature of the relationship, subtypes at risk, and treatment issues. Psychiatry Clin North Am 2004;27:283-301.

-24 Frodl T: Comorbidity of ADHD and substance use disorder (SUD): a neuroimaging perspective. J Atten Disord 2010;14:109-120.

25 Davis L, Uezato A, Newell JM, Frazier E: Major depression and comorbid substance use disorders. Curr Opin Psychiatry 2008;21:14-18.

26 Hasin D, Liu X, Nunes E, McCloud S, Samet S, Endicott J: Effects of major depression on remission and relapse of substance dependence. Arch Gen Psychiatry 2002;59:375-380.

-27 Tossmann P, Boldt S, Tensil MD: The use of drugs within the techno party scene in European metropolitan cities. Eur Addict Res 2001;7:2-23.

-28 Reboussin BA, Anthony JC: Is there epidemiological evidence to support the idea that a cocaine dependence syndrome emerges soon after onset of cocaine use? Neuropsychopharmacology 2006;31:2055-2064.

29 Kreek MJ, Nielsen DA, Butelman ER, LaForge KS: Genetic influences on impulsivity, risk taking, stress responsivity and vulnerability to drug abuse and addiction. Nat Neurosci 2005;8:1450-1457.

-30 Nigg JT, Wong MM, Martel MM, Jester JM, Puttler LI, Glass JM, Adams KM, Fitzgerald HE, Zucker RA: Poor response inhibition as a predictor of problem drinking and illicit drug use in adolescents at risk for alcoholism and other substance use disorders. J Am Acad Child Adolesc Psychiatry 2006;45:468-475.

-31 Audrain-McGovern J, Rodriguez D, Epstein LH, Cuevas J, Rodgers K, Wileyto EP: Does delay discounting play an etiological role in smoking or is it a consequence of smoking? Drug Alcohol Depend 2009;103:99-106.

-32 Jentsch JD, Taylor JR: Impulsivity resulting from frontostriatal dysfunction in drug abuse: implications for the control of behavior by reward-related stimuli. Psychopharmacology (Berl) 1999;146:373-390.

-33 Jentsch JD: Impulsivity in Animal Models for Drug Abuse Disorders. Drug Discov Today Dis Models 2008;5: 247-250.

34 Nederkoorn C, Smulders FTY, Havermans RC, Roefs A, Jansen A: Impulsivity in obese women. Appetite 2006;47:253-256.

-35 Braet C, Claus L, Verbeken S, van Vlierberghe L: Impulsivity in overweight children. Eur Child Adolesc Psychiatry 2007;16:473-483.

36 Perry JL, Carroll ME: The role of impulsive behavior in drug abuse. Psychopharmacology (Berl) 2008;200: $1-26$.

37 Nederkoorn C, Braet C, van Eijs Y, Tanghe A, Jansen A: Why obese children cannot resist food: the role of impulsivity. Eat Behav 2006;7:315-322.

-38 Nederkoorn C, Jansen E, Mulkens S, Jansen A: Impulsivity predicts treatment outcome in obese children. Behav Res Ther 2007;45:1071-1075.

-39 Mitchell SH: Measures of impulsivity in cigarette smokers and non-smokers. Psychopharmacology (Berl) 1999;146:455-464. 
-40 Bowden-Jones H, McPhillips M, Rogers R, Hutton S, Joyce E: Risk-taking on tests sensitive to ventromedial prefrontal cortex dysfunction predicts early relapse in alcohol dependency: a pilot study. J Neuropsychiatry Clin Neurosci 2005;17:417-420.

-41 Paulus MP, Tapert SF, Schuckit MA: Neural activation patterns of methamphetamine-dependent subjects during decision making predict relapse. Arch Gen Psychiatry 2005;62:761-768.

$\$ 42$ Moeller FG, Dougherty DM, Barratt ES, Schmitz JM, Swann AC, Grabowski J: The impact of impulsivity on cocaine use and retention in treatment. J Subst Abuse Treat 2001;21:193-198.

-43 Krishnan-Sarin S, Reynolds B, Duhig AM, Smith A, Liss T, McFetridge A, Cavallo DA, Carroll KM, Potenza MN: Behavioral impulsivity predicts treatment outcome in a smoking cessation program for adolescent smokers. Drug Alcohol Depend 2007;88:79-82.

44 Koob GF, Volkow ND: Neurocircuitry of addiction. Neuropsychopharmacology 2010;35:217-238.

$\checkmark 45$ Everitt BJ, Robbins TW: Neural systems of reinforcement for drug addiction: from actions to habits to compulsion. Nat Neurosci 2005;8:1481-1489.

-46 Kilts CD, Schweitzer JB, Quinn CK, Gross RE, Faber TL, Muhammad F, Ely TD, Hoffman JM, Drexler KP: Neural activity related to drug craving in cocaine addiction. Arch Gen Psychiatry 2001;58:334-341.

47 Filbey FM, Schacht JP, Myers US, Chavez RS, Hutchison KE: Marijuana craving in the brain. Proc Natl Acad Sci U S A 2009;106:13016-13021.

-48 Kober H, Mende-Siedlecki P, Kross EF, Weber J, Mischel W, Hart CL, Ochsner KN: Prefrontal-striatal pathway underlies cognitive regulation of craving. Proc Natl Acad Sci U S A 2010;107:14811-14816.

49 Childress AR, Mozley PD, McElgin W, Fitzgerald J, Reivich M, O’Brien CP: Limbic activation during cueinduced cocaine craving. Am.J.Psychiatry 1999;156:11-18.

-50 Garavan H, Pankiewicz J, Bloom A, Cho JK, Sperry L, Ross TJ, Salmeron BJ, Risinger R, Kelley D, Stein EA: Cue-induced cocaine craving: neuroanatomical specificity for drug users and drug stimuli. Am J Psychiatry 2000;157:1789-1798.

-51 Pelchat ML, Johnson A, Chan R, Valdez J, Ragland JD: Images of desire: food-craving activation during fMRI. Neuroimage 2004;23:1486-1493.

$\$ 52$ Rolls ET, McCabe C: Enhanced affective brain representations of chocolate in cravers vs. non-cravers. Eur J Neurosci 2007;26:1067-1076.

53 Miller EK, Cohen JD: An integrative theory of prefrontal cortex function. Annu Rev Neurosci 2001;24:167202.

54 Gearhardt AN, Yokum S, Orr PT, Stice E, Corbin WR, Brownell KD: Neural correlates of food addiction. Arch Gen Psychiatry 2011;68:808-816.

-55 van den Eynde F, Claudino AM, Mogg A, Horrell L, Stahl D, Ribeiro W, Uher R, Campbell I, Schmidt U: Repetitive transcranial magnetic stimulation reduces cue-induced food craving in bulimic disorders. Biol Psychiatry 2010;67:793-795.

56 Pelchat ML: Of human bondage: food craving, obsession, compulsion, and addiction. Physiol Behav 2002; 76:347-352.

57 Wang G-J, Volkow ND, Logan J, Pappas NR, Wong CT, Zhu W, Netusil N, Fowler JS: Brain dopamine and obesity. Lancet 2001;357:354-357.

-58 Volkow ND, Wang G-J, Fowler JS, Telang F: Overlapping neuronal circuits in addiction and obesity: evidence of systems pathology. Philos Trans R Soc Lond B Biol Sci 2008;363:3191-3200.

$\checkmark 59$ Volkow ND, Wang G-J, Telang F, Fowler JS, Thanos PK, Logan J, Alexoff D, Ding Y-S, Wong C, Ma Y, et al: Low dopamine striatal D2 receptors are associated with prefrontal metabolism in obese subjects: possible contributing factors. Neuroimage 2008;42:1537-1543.

-60 Stice E, Spoor S, Bohon C, Small DM: Relation between obesity and blunted striatal response to food is moderated by TaqIA A1 allele. Science 2008;322:449-452.

61 Noble EP: D2 dopamine receptor gene in psychiatric and neurologic disorders and its phenotypes. Am J Med Genet B Neuropsychiatr Genet 2003;116B:103-125.

-62 Morgan D, Grant KA, Gage HD, Mach RH, Kaplan JR, Prioleau O, Nader SH, Buchheimer N, Ehrenkaufer RL, Nader MA: Social dominance in monkeys: dopamine D2 receptors and cocaine self-administration. Nat Neurosci 2002;5:169-174.

63 Dalley JW, Fryer TD, Brichard L, Robinson ESJ, Theobald DEH, Lääne K, Peña Y, Murphy ER, Shah Y, Probst $\mathrm{K}$, et al: Nucleus accumbens D2/3 receptors predict trait impulsivity and cocaine reinforcement. Science 2007;315:1267-1270.

64 Volkow ND, Wang G-J, Fowler JS, Thanos PPK, Logan J, Gatley SJ, Gifford A, Ding Y-S, Wong C, Pappas N, et al: Brain DA D2 receptors predict reinforcing effects of stimulants in humans: replication study. Synapse 2002;46:79-82.

65 Volkow ND, Wang G-J, Fowler JS, Logan J, Gatley SJ, Gifford A, Hitzemann R, Ding YS, Pappas N: Prediction of reinforcing responses to psychostimulants in humans by brain dopamine D2 receptor levels. Am J Psychiatry 1999;156:1440-1443.

66 Porrino LJ, Daunais JB, Smith HR, Nader MA: The expanding effects of cocaine: studies in a nonhuman primate model of cocaine self-administration. Neurosci Biobehav Rev 2004;27:813-820.

-67 Nader MA, Daunais JB, Moore T, Nader SH, Moore RJ, Smith HR, Friedman DP, Porrino LJ: Effects of cocaine self-administration on striatal dopamine systems in rhesus monkeys: initial and chronic exposure. Neuropsychopharmacology 2002;27:35-46. 
68 Kelley AE, Bakshi VP, Haber SN, Steininger TL, Will MJ, Zhang M: Opioid modulation of taste hedonics within the ventral striatum. Physiol Behav 2002;76:365-377.

69 Peciña S, Smith KS: Hedonic and motivational roles of opioids in food reward: Implications for overeating disorders. Pharmacol Biochem Behav 2010;97:34-46.

-70 Yeomans MR, Gray RW: Effects of naltrexone on food intake and changes in subjective appetite during eating: evidence for opioid involvement in the appetizer effect. Physiol Behav 1997;62:15-21.

71 Drewnowski A, Krahn DD, Demitrack MA, Nairn K, Gosnell BA: Naloxone, an opiate blocker, reduces the consumption of sweet high-fat foods in obese and lean female binge eaters. Am J Clin Nutr 1995;61:12061212.

72 Trigo JM, Martin-García E, Berrendero F, Robledo P, Maldonado R: The endogenous opioid system: a common substrate in drug addiction. Drug Alcohol Depend 2010;108:183-194.

73 Shaham Y, Shalev U, Lu L, de Wit H, Stewart J: The reinstatement model of drug relapse: history, methodology and major findings. Psychopharmacology (Berl) 2003;168:3-20.

74 Panlilio LV, Goldberg SR: Self-administration of drugs in animals and humans as a model and an investigative tool. Addiction 2007;102:1863-1870.

75 Bossert JM, Ghitza UE, Lu L, Epstein DH, Shaham Y: Neurobiology of relapse to heroin and cocaine seeking: an update and clinical implications. Eur J Pharmacol 2005;526:36-50.

-76 Richardson NR, Roberts DC: Progressive ratio schedules in drug self-administration studies in rats: a method to evaluate reinforcing efficacy. J Neurosci Methods 1996;66:1-11.

77 Pelloux Y, Everitt BJ, Dickinson A: Compulsive drug seeking by rats under punishment: effects of drug taking history. Psychopharmacology (Berl) 2007;194:127-137.

78 Deroche-Gamonet V, Belin D, Piazza PV: Evidence for addiction-like behavior in the rat. Science 2004;305: 1014-1017.

79 Lesscher HMB, van Kerkhof LWM, Vanderschuren LJMJ: Inflexible and indifferent alcohol drinking in male mice. Alcoholism, clinical and experimental research 2010;34:1219-1225.

80 Wolffgramm J, Heyne A: From controlled drug intake to loss of control: the irreversible development of drug addiction in the rat. Behav Brain Res 1995;70:77-94.

81 Hopf FW, Chang S-J, Sparta DR, Bowers MS, Bonci A: Motivation for alcohol becomes resistant to quinine adulteration after 3 to 4 months of intermittent alcohol self-administration. Alcohol Clin Exp Res 2010;34: 1565-1573.

82 Vanderschuren LJMJ, Everitt BJ: Drug seeking becomes compulsive after prolonged cocaine self-administration. Science 2004;305:1017-1019.

-83 Lenoir M, Ahmed SH: Heroin-induced reinstatement is specific to compulsive heroin use and dissociable from heroin reward and sensitization. Neuropsychopharmacology 2007;32:616-624.

$\$ 84$ Lenoir M, Serre F, Cantin L, Ahmed SH: Intense sweetness surpasses cocaine reward. PLoS ONE 2007; 2:e698.

85 Belin D, Mar AC, Dalley JW, Robbins TW, Everitt BJ: High impulsivity predicts the switch to compulsive cocaine-taking. Science 2008;320:1352-1355.

86 Piazza PV, Deminière JM, Le Moal M, Simon H: Factors that predict individual vulnerability to amphetamine self-administration. Science 1989,245:1511-1513.

-87 Piazza PV, Deroche-Gamonent V, Rougé-Pont F, Le Moal M: Vertical shifts in self-administration doseresponse functions predict a drug-vulnerable phenotype predisposed to addiction. Journal of Neuroscience 2000,20:4226-4232.

-88 Dalley JW, Everitt BJ, Robbins TW: Impulsivity, compulsivity, and top-down cognitive control. Neuron 2011,69:680-694.

89 McNamara R, Dalley JW, Robbins TW, Everitt BJ, Belin D: Trait-like impulsivity does not predict escalation of heroin self-administration in the rat. Psychopharmacology (Berl) 2010,212:453-464.

$\$ 90$ Molander AC, Mar A, Norbury A, Steventon S, Moreno M, Caprioli D, Theobald DEH, Belin D, Everitt BJ, Robbins TW, et al: High impulsivity predicting vulnerability to cocaine addiction in rats: some relationship with novelty preference but not novelty reactivity, anxiety or stress. Psychopharmacology (Berl) 2011,215: 721-731.

91 Poulos CX, Lê AD, Parker JL: Impulsivity predicts individual susceptibility to high levels of alcohol selfadministration. Behav Pharmacol 1995;6:810-814.

-92 Perry JL, Larson EB, German JP, Madden GJ, Carroll ME: Impulsivity (delay discounting) as a predictor of acquisition of IV cocaine self-administration in female rats. Psychopharmacology (Berl) 2005;178:193201.

\$3 Diergaarde L, Pattij T, Poortvliet I, Hogenboom F, de Vries W, Schoffelmeer ANM, de Vries TJ: Impulsive choice and impulsive action predict vulnerability to distinct stages of nicotine seeking in rats. Biol Psychiatry 2008;63:301-308.

$\$ 94$ Schippers MC, Binnekade R, Schoffelmeer ANM, Pattij T, de Vries TJ: Unidirectional relationship between heroin self-administration and impulsive decision-making in rats. Psychopharmacology (Berl) 2012;219: 443-452.

95 Cantin L, Lenoir M, Augier E, Vanhille N, Dubreucq S, Serre F, Vouillac C, Ahmed SH: Cocaine is low on the value ladder of rats: possible evidence for resilience to addiction. PLoS ONE 2010;5:e11592. 
$\$ 96$ Lenoir M, Ahmed SH: Supply of a nondrug substitute reduces escalated heroin consumption. Neuropsychopharmacology 2008;33:2272-2282.

-97 Kasanetz F, Deroche-Gamonet V, Berson N, Balado E, Lafourcade M, Manzoni O, Piazza PV: Transition to addiction is associated with a persistent impairment in synaptic plasticity. Science 2010;328:1709-1712.

$\$ 9$ La Fleur SE, van Rozen AJ, Luijendijk MCM, Groeneweg F, Adan RAH: A free-choice high-fat high-sugar diet induces changes in arcuate neuropeptide expression that support hyperphagia. Int J Obes (Lond) 2010;34: 537-546.

\$9 Lieblich I, Cohen E, Ganchrow JR, Blass EM, Bergmann F: Morphine tolerance in genetically selected rats induced by chronically elevated saccharin intake. Science 1983;221:871-873.

100 Knapp CM, Kornetsky C: Bromocriptine, a D2 receptor agonist, lowers the threshold for rewarding brain stimulation. Pharmacol Biochem Behavr 1994;49:901-904.

101 Esposito RU, Motola AH, Kornetsky C: Cocaine: acute effects on reinforcement thresholds for self-stimulation behavior to the medial forebrain bundle. Pharmacol, Biochem Behav 1978;8:437-439.

102 Wise RA: Addictive drugs and brain stimulation reward. Annu Rev Neurosci 1996;19:319-340.

103 Markou A, Koob GF: Postcocaine anhedonia. An animal model of cocaine withdrawal. Neuropsychopharmacology 1991;4:17-26.

104 Johnson PM, Kenny PJ: Dopamine D2 receptors in addiction-like reward dysfunction and compulsive eating in obese rats. Nat Neurosci 2010;13:635-641.

105 Markou A, Koob GF: Bromocriptine reverses the elevation in intracranial self-stimulation thresholds observed in a rat model of cocaine withdrawal. Neuropsychopharmacology 1992;7:213-224.

106 Avena NM, Hoebel BG: A diet promoting sugar dependency causes behavioral cross-sensitization to a low dose of amphetamine. Neuroscience 2003;122:17-20.

107 Colantuoni C, Schwenker J, McCarthy J, Rada P, Ladenheim B, Cadet JL, Schwartz GJ, Moran TH, Hoebel BG: Excessive sugar intake alters binding to dopamine and mu-opioid receptors in the brain. Neuroreport 2001;12:3549-3552.

108 Bello NT, Lucas LR, Hajnal A: Repeated sucrose access influences dopamine D2 receptor density in the striatum. Neuroreport 2002;13:1575-1578.

109 Koob GF: A role for brain stress systems in addiction. Neuron 2008;59:11-34.

110 Dallman MF: Stress-induced obesity and the emotional nervous system. Trends Endocrinol Metab 2010;21: 159-165.

111 Parylak SL, Koob GF, Zorrilla EP: The dark side of food addiction. Physiol Behav 2011;104:149-156.

112 Hagan MM, Wauford PK, Chandler PC, Jarrett LA, Rybak RJ, Blackburn K: A new animal model of binge eating: key synergistic role of past caloric restriction and stress. Physiol Behav 2002;77:45-54.

113 Hagan MM, Chandler PC, Wauford PK, Rybak RJ, Oswald KD: The role of palatable food and hunger as trigger factors in an animal model of stress induced binge eating. Int J Eat Disord 2003;34:183-197.

-114 Cifani C, Polidori C, Melotto S, Ciccocioppo R, Massi M: A preclinical model of binge eating elicited by yo-yo dieting and stressful exposure to food: effect of sibutramine, fluoxetine, topiramate, and midazolam. Psychopharmacology (Berl) 2009;204:113-125.

115 Pankevich DE, Teegarden SL, Hedin AD, Jensen CL, Bale TL: Caloric restriction experience reprograms stress and orexigenic pathways and promotes binge eating. J Neurosci 2010;30:16399-16407.

116 Buczek Y, Lê AD, Wang A, Stewart J, Shaham Y: Stress reinstates nicotine seeking but not sucrose solution seeking in rats. Psychopharmacology (Berl) 1999;144:183-188.

117 Ahmed SH, Koob GF: Cocaine- but not food-seeking behavior is reinstated by stress after extinction. Psychopharmacology (Berl) 1997;132:289-295.

118 Paterson NE, Markou A: Increased motivation for self-administered cocaine after escalated cocaine intake. Neuroreport 2003;14:2229-2232.

119 Wee S, Mandyam CD, Lekic DM, Koob GF: Alpha 1-noradrenergic system role in increased motivation for cocaine intake in rats with prolonged access. Eur Neuropsychopharmacol 2008;18:303-311.

120 Orio L, Edwards S, George O, Parsons LH, Koob GF: A role for the endocannabinoid system in the increased motivation for cocaine in extended-access conditions. J Neurosci 2009;29:4846-4857.

121 Liu Y, Roberts DCS, Morgan D: Effects of extended-access self-administration and deprivation on breakpoints maintained by cocaine in rats. Psychopharmacology (Berl) 2005;179:644-651.

122 Morgan D, Liu Y, Roberts DCS: Rapid and persistent sensitization to the reinforcing effects of cocaine. Neuropsychopharmacology 2006;31:121-128.

123 La Fleur SE, Vanderschuren LJMJ, Luijendijk MC, Kloeze BM, Tiesjema B, Adan RAH: A reciprocal interaction between food-motivated behavior and diet-induced obesity. Int J Obes (Lond) 2007;31:1286-1294.

124 Wojnicki FHE, Roberts DCS, Corwin RLW: Effects of baclofen on operant performance for food pellets and vegetable shortening after a history of binge-type behavior in non-food deprived rats. Pharmacol Biochem Behav 2006;84:197-206.

125 Ghitza UE, Gray SM, Epstein DH, Rice KC, Shaham Y: The anxiogenic drug yohimbine reinstates palatable food seeking in a rat relapse model: a role of CRF1 receptors. Neuropsychopharmacology 2006;31:21882196.

126 Dickinson A, Wood N, Smith JW: Alcohol seeking by rats: action or habit? Q J Exp Psychol B 2002;55:331348. 
127 Miles FJ, Everitt BJ, Dickinson A: Oral cocaine seeking by rats: action or habit? Behav Neurosci 2003;117: 927-938.

128 Latagliata EC, Patrono E, Puglisi-Allegra S, Ventura R: Food seeking in spite of harmful consequences is under prefrontal cortical noradrenergic control. BMC Neurosci 2010;11:15.

129 Oswald KD, Murdaugh DL, King VL, Boggiano MM: Motivation for palatable food despite consequences in an animal model of binge eating. Int J Eat Disord 2011;44:203-211.

130 Heyne A, Kiesselbach C, Sahún I, McDonald J, Gaiffi M, Dierssen M, Wolffgramm J: An animal model of compulsive food-taking behaviour. Addict Biol 2009;14:373-383.

131 Wolffgramm J: An ethopharmacological approach to the development of drug addiction. Neurosci Biobehav Rev 1991;15:515-519.

-132 Sarnyai Z, Bíró E, Gardi J, Vecsernyés M, Julesz J, Telegdy G: Brain corticotropin-releasing factor mediates 'anxiety-like' behavior induced by cocaine withdrawal in rats. Brain Res 1995;675:89-97.

133 Nair SG, Adams-Deutsch T, Epstein DH, Shaham Y: The neuropharmacology of relapse to food seeking: methodology, main findings, and comparison with relapse to drug seeking. Prog Neurobiol 2009;89:18-45.

134 Weingarten HP: Conditioned cues elicit feeding in sated rats: a role for learning in meal initiation. Science 1983;220:431-433.

135 Boggiano MM, Dorsey JR, Thomas JM, Murdaugh DL: The Pavlovian power of palatable food: lessons for weight-loss adherence from a new rodent model of cue-induced overeating. Int J Obes (Lond) 2009;33: 693-701.

136 Jansen A: A learning model of binge eating: cue reactivity and cue exposure. Behav Res Ther 1998;36:257272.

137 Pelchat ML: Food addiction in humans. J Nutr 2009;139:620-622.

138 Hagan MM, Moss DE: Persistence of binge-eating patterns after a history of restriction with intermittent bouts of refeeding on palatable food in rats: implications for bulimia nervosa. Int J Eat Disord 1997;22: 411-420.

139 Hagan MM, Shuman ES, Oswald KD, Corcoran KJ, Profitt JH, Blackburn K, Schwiebert MW, Chandler PC, Birbaum MC: Incidence of chaotic eating behaviors in binge-eating disorder: contributing factors. Behav Med 2006;28:99-105.

140 Diergaarde L, Pattij T, Nawijn L, Schoffelmeer ANM, de Vries TJ: Trait impulsivity predicts escalation of sucrose seeking and hypersensitivity to sucrose-associated stimuli. Behav Neurosci 2009;123:794-803.

141 Belin D, Balado E, Piazza PV, Deroche-Gamonet V: Pattern of intake and drug craving predict the development of cocaine addiction-like behavior in rats. Biol Psychiatry 2009;65:863-868.

142 Duarte C, Biala G, Le Bihan C, Hamon M, Thiébot M-H: Respective roles of dopamine D2 and D3 receptors in food-seeking behaviour in rats. Psychopharmacology (Berl) 2003;166:19-32.

143 Angeles-Castellanos M, Mendoza J, Escobar C: Restricted feeding schedules phase shift daily rhythms of c-Fos and protein Per1 immunoreactivity in corticolimbic regions in rats. Neuroscience 2007;144:344355.

144 Porrino LJ, Lyons D, Smith HR, Daunais JB, Nader MA: Cocaine self-administration produces a progressive involvement of limbic, association, and sensorimotor striatal domains. J Neurosci 2004;24:3554-3562.

145 Volkow ND, Wang G-J, Ma Y, Fowler JS, Wong C, Ding Y-S, Hitzemann R, Swanson JM, Kalivas P: Activation of orbital and medial prefrontal cortex by methylphenidate in cocaine-addicted subjects but not in controls: relevance to addiction. J Neurosci 2005;25:3932-3939.

146 Pierce RC, Vanderschuren LJMJ: Kicking the habit: the neural basis of ingrained behaviors in cocaine addiction. Neurosci Biobehav Rev 2010;35:212-219. 